\title{
Erratum to: Novel hyaluronic acid- methotrexate conjugate suppresses joint inflammation in the rat knee: efficacy and safety evaluation in two rat arthritis models
}

Tatsuya Tamura ${ }^{1 *}$, Yoshinobu Higuchi ${ }^{1}$, Hidetomo Kitamura ${ }^{1}$, Naoaki Murao ${ }^{1}$, Ryoichi Saitoh', Tadashi Morikawa ${ }^{2}$ and Haruhiko Sato ${ }^{1}$

After publication of this article [1] it was noticed that Figs. 2 and 4 (seen below) contained incorrect characters. The corrected figures can be seen below and the original article has also been updated to reflect this.

\section{Author details}

${ }^{1}$ Research Division, Chugai Pharmaceutical Co., Ltd., 1-135 Komakado, Gotemba, Shizuoka 412-8513, Japan. ${ }^{2}$ New Business Planning Department, Denka Co., Ltd., 2-1-1 Nihonbashi-Muromachi, Chuo-ku, Tokyo 103-8338,

Japan.

Received: 18 May 2016 Accepted: 19 May 2016

Published online: 31 May 2016

\section{Reference}

1. Tatsuya T, Yoshinobu H, Hidetomo K, Naoaki M, Ryoichi S, Tadashi M,

Haruhiko S. Novel hyaluronic acid-methotrexate conjugate suppresses joint inflammation in the rat knee: efficacy and safety evaluation in two rat arthritis models. Arthritis Res Ther. 2016;18:79. doi:10.1186/s13075-016-0971-8.

\footnotetext{
*Correspondence: tamuratty@chugai-pharm.co.jp

${ }^{1}$ Research Division, Chugai Pharmaceutical Co., Ltd., 1-135 Komakado,

Gotemba, Shizuoka 412-8513, Japan

Full list of author information is available at the end of the article

Submit your next manuscript to BioMed Central and we will help you at every step:

- We accept pre-submission inquiries

- Our selector tool helps you to find the most relevant journal

- We provide round the clock customer support

- Convenient online submission

- Thorough peer review

- Inclusion in PubMed and all major indexing services

- Maximum visibility for your research

Submit your manuscript at

www.biomedcentral.com/submit 
a

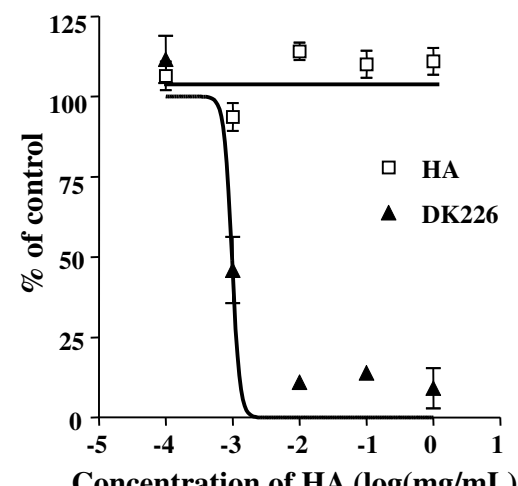

Concentration of HA $(\log (\mathrm{mg} / \mathrm{mL}))$

C

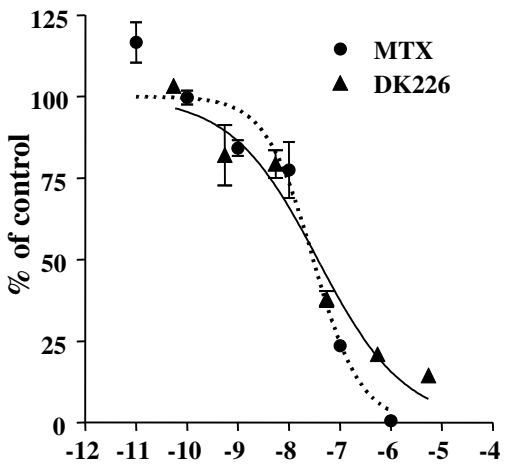

b

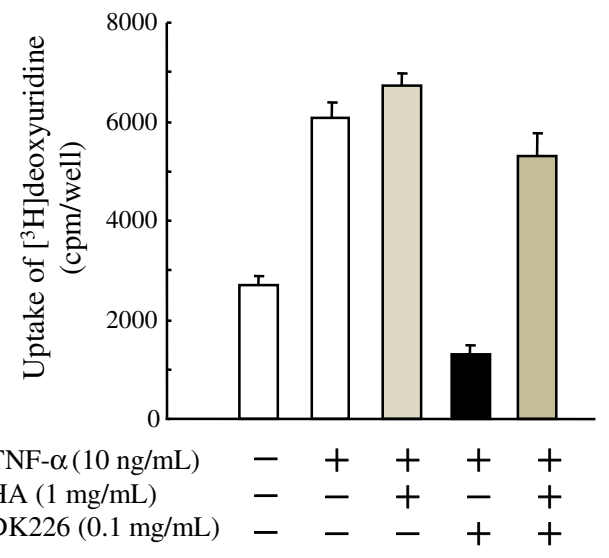

d

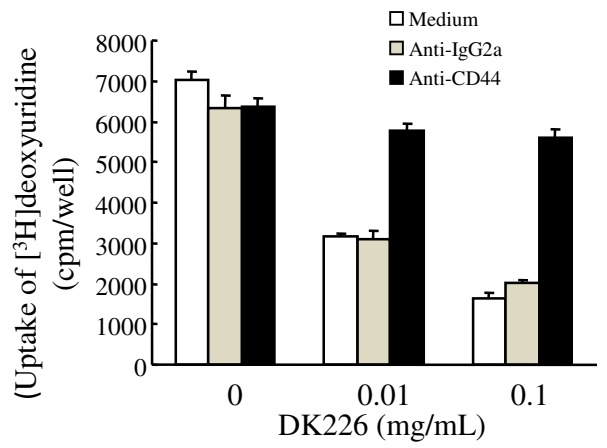

Fig. 2 Effect of DK226 on proliferation of human synovial fibroblast-like cells (HFLS) and of human synovial sarcoma cell line SW982. a Inhibition of tumor necrosis alpha (TNF-a)-induced proliferation of HFLS by hyaluronic acid (HA) or DK226 at increasing, equivalent HA concentrations. b Effect of exogenously added HA on the anti-proliferative effect of DK226 in HFLS. c Inhibition of proliferation of SW982 by methotrexate (MTX) or DK226 at increasing, equivalent MTX concentrations. $\mathbf{d}$ Effect of exogenously added anti-CD44 antibody (BU75) and anti-lgG2a (control antibody) on the anti-proliferative effect of DK226 in SW982. Values are means and standard error of the mean (SEM) $(n=4)$ 


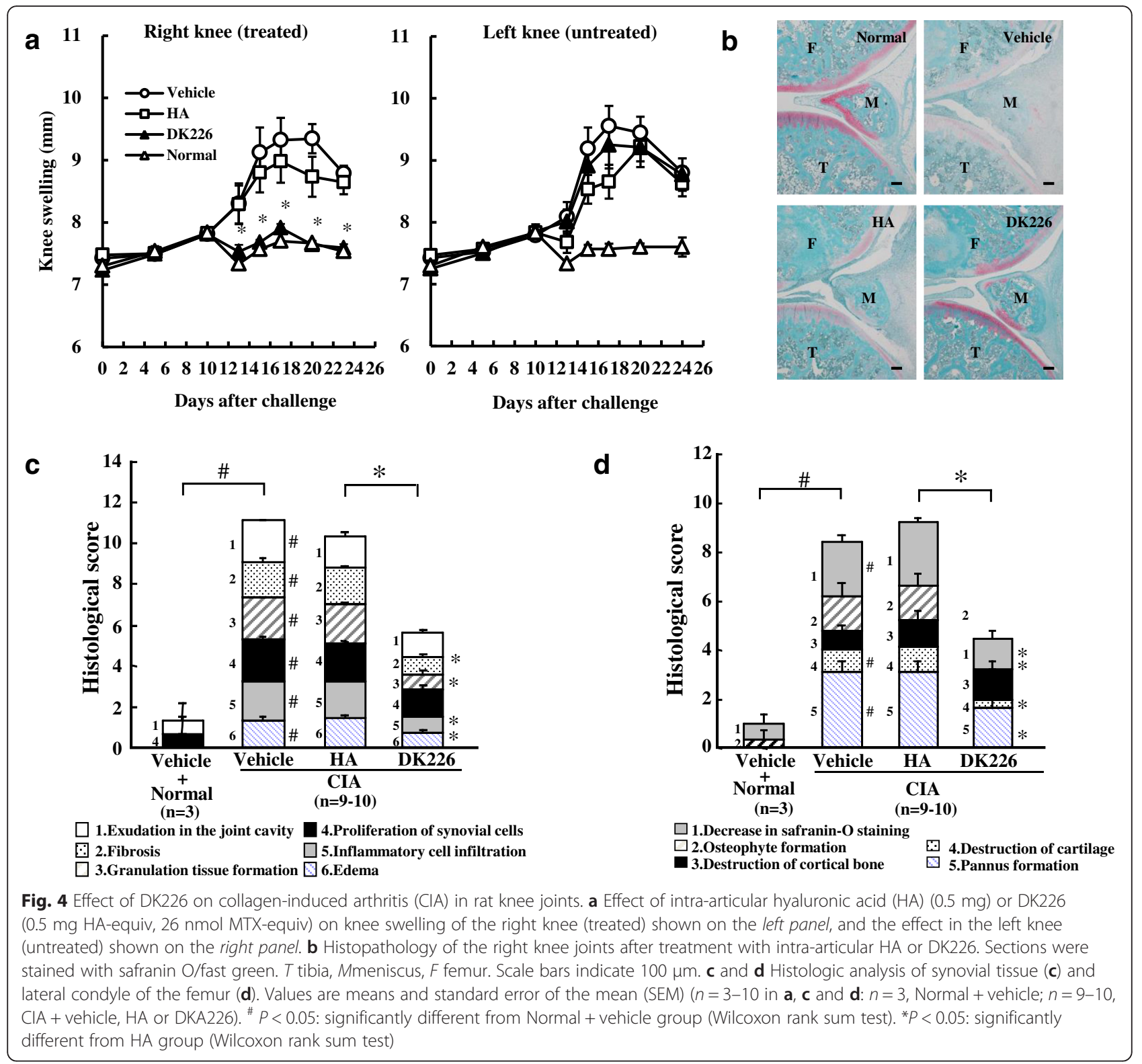

